\title{
TECHNOLOGICAL RISK IN THE CONTEXT OF PROCESS APPROACH AND RISK ASSESSMENT
}

doi:10.2478/czoto-2021-0033

Date of submission of the article to the Editor: 06/12/2020

Date of acceptance of the article by the Editor: 24/03/2021

Tatiana Karkoszka ${ }^{1}$ - orcid id: 0000-0002-7853-3654

${ }^{1}$ Silesian University of Technology, Poland

\begin{abstract}
The processes effectiveness means their ability to achieve the planned aims. While planning the aims, one should currently take into consideration not only the quality parameters but also all of the criteria reflecting the expectations stated by the interested parties. Influence on the processes by the factors disturbing their realization requires such their monitoring and regulation to make the aims achievable. In return, it requires development and application of the processes assessment methods enabling pointing out their pivotal points and the possibilities of their monitoring. The study proposes the following combination: process approach and risk assessment enabling pointing out the "risky" processes as well as their "risky" aspects. The risk of the particular process has been evaluated by taking advantage of two methods considering various risk parameters as well as various individual criteria for assessing the mentioned parameters. Application of the developed methodologies of risk analysis and assessment of its acceptability allowed for formulating the conclusion that while risk assessment the following aspects are important: choice of the risk parameters, application of the individual assessment criteria of these parameters and taking advantage of the risk acceptability scale of the process, depending on the phase of its improvement. Properly prepared method of risk assessment gives the chance for the effective monitoring of the process risk refraining from its particular threats.
\end{abstract}

Keywords: process risk, risk assessment, risk acceptability, process approach

\section{INTRODUCTION}

The principal element of the production process represents the technological process, during which occur change of the shape, dimensions and the physicochemical features of the manufactured parts or goods and their putting together into units or ready final product. Since the technological quality is related to the proper realization of the manufacturing process as well as the condition of the machines and the technological devices, the crucial importance regarding the process is its monitoring. It is realized by the measurements of the current values describing the condition of the process or devices, confirmation of the compliance of the obtained values with the established criteria, current monitoring enabling identification of the deregulations 
within the process as well as the control directed at the stabilization of its realization (Gawlik et al., 2013).

The choice of the particular technology depends not only on the basic criteria, especially the market and technical-organizational ones, but also economic, social and ecological criteria (Gawlik et al., 2013). Ensuring - with the regard of the mentioned various criteria - the effectiveness of the technological processes is possible by process management being realized among others by implementation of the management systems.

According to the process approach "Consistent and predictable results are achieved more effectively and efficiently when activities are understood and managed as interrelated processes that function as a coherent system (ISO 9001, 2015)", which means acceptance of the focus on management of various processes as well as the process management of organization aiming at enlarging the flexibility of all the system by optimization of its specified processes (Grajewski, 2012; Hernas and Gajda, 2005; Lisichkina, 2015; Skrzypek, 2008; Skrzypek and Hoffman, 2010).

The process management of the organization can be defined as planning, organizing and monitoring of the processes system as well as searching the possibilities of its improvement. Application of such a management conception should be proceeded by identification and analysis of the particular processes (Grajewski, 2012; Skrzypek and Hoffman, 2010). This should enable characterizing all of the determinants of its planned course (Skrzypek and Hoffman, 2010):

- input factors such as human resources and financial ones, infrastructure together with the environment of the realized process,

- output factors such as tangible and non-tangible products, both: these expected by the clients as well as these being the side-effect of the realized process,

- indispensable actions for beginning the analysed process,

- interactions with the other processes creating the whole system,

- criteria of the processes realization being the reflection of the model process,

- rules and tools for the measurement and the methods for the conformity estimation with the defined process criteria.

Verification of the processes effectiveness, meaning the conformity with the planned and described process criteria, is the confirmation of the assumed aims realization. However, each of the process is exposed to the disturbing factors causing not being able to fulfill the planned expectations. As a consequence, it requires monitoring, regulation and improvement of the process (Zymonik et al., 2013).

Due to the mentioned above, realization of the processes must be proceeded by planning the actions enabling fulfilling the stated requirements within the processes. While planning one should remember about the following:

- various processes have various meaning for the system functioning,

- various processes are exposed to various factors,

- within various processes various criteria are of meaningful importance.

Processes stakeholders who are exposed to technological threats should be informed about their negative effects and be prepared to avoid them (Renn and Benighaus, 2013). Therefore, on the planning phase indispensable is application of the tool, which on one hand allows for pointing out the "problematic" processes, and on the other hand enables identification and monitoring on the key-parameters of these processes. Such a tool can be risk reflecting the probability and the consequence of lack of the conformity with the processes criteria.Defining the risk included, while processes 
planning is justified, and as a consequence, ensuring the minimizing monitored environmental conditions. To manage the processes in a proper way, one should exposed them, depending on the risk level involved within the process, to the improving - Fig. 1.

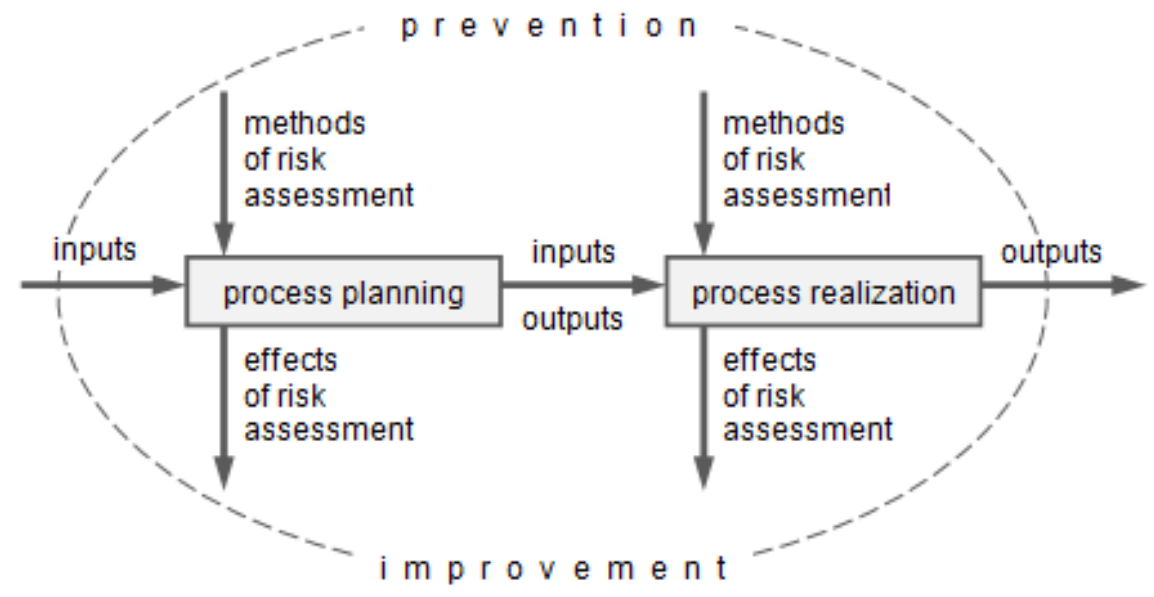

Fig. 1. Scheme of the process improvement based on the risk assessment

One should underline that process planning, so far being interpreted as quality planning, must be replaced by the integrated planning of the process taking into consideration expectations stated by various interested parties as well as the environmental and work safety factors. On the other hand, base of the formal integration within the management in the organizations was stated and promoted by the ISO 9001, ISO 14001 and ISO 45001 standards, representing the following approach: process, systemic and risk based one.

\section{METHODOLOGY}

Within the planning the particular organization, considering both: internal and external factors having influence on the organization as well as the risk involved, identifies the aims and arranges the ways of achieving them.

While identifying the risk, the organization especially considers the following: legal and other applicable requirements, workplace safety threats, environmental aspects as well as the other requirements connected with the fulfilment of internal and external requirements stated by various interested parties. Moreover, while establishing the actions connected with risk taking, the organization should integrate these actions with the management system processes, and finally assess their effectiveness.

Regardless the organization uses in its systemic actions the risk elements, there is no standard requiring any formalised risk management as well as pointing any particular method of risk assessment. It requires from the organization developing the own procedure of risk assessment, including the way of its assessment.

Identification of the processes, proceeding the analysis and the risk assessment, must be realized with the regard of risk assessment. It means, that already at the identification phase, the particular organization should define if it will be performing the risk assessment exclusively within the scope of the quality requirements or it will take into account the environmental context as well as workplace safety or other contexts. 
Threats identification as well as the risk assessment also should be realized in the context of the chosen scope of the assessment. As the consequence, to perform the risk analysis and estimate its acceptability - the particular organization must prepare the individual criteria for analysing and assessment. The mentioned criteria depend not only on the assessment scope but also on the considered parameters during risk defining by the organization. Within the technical context, the risk is most often described as "combination of the incidence or appearance probability of the particular dangerous occurrence and the consequences connected with this occurrence (IEC $60300-3-9,1995)$ ), therefore, the most often considered by the organizations within the process risk assessment are two parameters - the probability of threats effects occurrence and the significance of them. It refrains not only from the risk definition itself but also from the labour law requirements, which within the risk assessment require from the employer exclusively the risk probability and effects assessment.

However, the most important within the risk analysis assessment is the proper choice of analysed parameters, which in turn would reflect the real risk accompanying the process. It also depends on the range of the analysed risk as well as on the kind of the analysed process, which means if the analysed process is the technological one or, for example the quality control process. Simultaneously, the choice of the analysed parameters determines the assessment criteria. The mentioned criteria should be of the individual character dedicated to the particular processes.

Risk ratio, being the reflection of the way of risk value assessment is also not of a book-case character. The organization must decide itself how it should look like. It is pivotal that the way of the risk assessment would be applied as a repeatable measure to ensure the comparability of the risk assessment results for various processes, at various phases of their improvement. The algorithms for evaluating the values of the single risk ratio for the method I, one has presented as the 1-3 equations. One also has assigned various individual assessment criteria (Tables 1-2). However, the algorithms for evaluating the values of the risk ratios as well as the individual assessment criteria applied for the method II are the subjects of the study (Karkoszka, 2017).

$$
R_{F}=S_{F} \cdot P_{F}(1) \quad R_{E}=S_{E} \cdot P_{E}(2) \quad R_{S}=S_{S} \cdot P_{S}(3)
$$

$\mathrm{R}_{F} / \mathrm{R}_{E} / \mathrm{R}_{S}$ - single risk ratio for failure/environmental impact/safety threat effect

$S_{F} / S_{E} / S_{S}$ - significance of failure/environmental impact/safety threat effect

$\mathrm{P}_{F} / \mathrm{P}_{E} / \mathrm{P}_{S}-$ probability of failure/environmental impact/safety threat effect

Table 1

Comparison of the criteria for significance assessment of failures, environmental influences and occupational threats effects

\begin{tabular}{|l|l|l|c|}
\hline Assessment criteria & Environmental & Occupational & Significance \\
Quality & SF $_{E} / S_{S}$ \\
\hline $\begin{array}{l}\text { No influence on the use } \\
\text { of the item }\end{array}$ & $\begin{array}{l}\text { No negative influence } \\
\text { on the natural } \\
\text { environment }\end{array}$ & Not causing threats & 1 \\
\hline $\begin{array}{l}\text { Not causing threats } \\
\text { while using the item }\end{array}$ & $\begin{array}{l}\text { Minimal influence } \\
\text { on the natural } \\
\text { environment- is ignored }\end{array}$ & $\begin{array}{l}\text { Light injuries (first aid } \\
\text { applied) }\end{array}$ & 2 \\
\hline
\end{tabular}




\begin{tabular}{|l|l|l|c|}
\hline $\begin{array}{l}\text { Using the item is } \\
\text { connected with threat }\end{array}$ & $\begin{array}{l}\text { Harmful influence } \\
\text { on the environment }\end{array}$ & $\begin{array}{l}\text { Medium injuries (few- } \\
\text { day absence at work) }\end{array}$ & 3 \\
\hline $\begin{array}{l}\text { The item cannot be } \\
\text { used as planned }\end{array}$ & $\begin{array}{l}\text { Irreversible harmful } \\
\text { and large-scale } \\
\text { influence on the } \\
\text { environment }\end{array}$ & $\begin{array}{l}\text { Heavy injuries } \\
\text { (few-months absence } \\
\text { at work) }\end{array}$ & 4 \\
\hline
\end{tabular}

\section{Table 2}

Comparison of the criteria for probability assessment of failures, environmental influences and occupational threats effects

\begin{tabular}{|l|c|}
\hline Assessment criteria & Probability $(P) P_{F} / P_{E} / P_{S}$ \\
\hline Little probable & 1 \\
\hline Once per month & 2 \\
\hline Often (once per week) & 3 \\
\hline Highly probable (every day) & 4 \\
\hline
\end{tabular}

The most crucial phase of the risk assessment is estimating its acceptability. Based on the outcome of this estimation, the organization takes up the decision how to act. The described methodology allows not only for defining the acceptability of the risk connected with the particular incompatibilities but also for the complex defining of the risk connected with the analysed technology - Fig. 2. Values of the ratios cannot be set "forever", since they depend on the current phase of improvement of the analysed process.

\begin{tabular}{|c|c|c|c|}
\hline $\begin{array}{c}\text { Aspect } \\
\text { acceptability }\end{array}$ & $\begin{array}{c}\text { Single Risk Ratio } \\
\text { R values }\end{array}$ & $\begin{array}{l}\text { Total Risk Ratio } \\
\sum \mathrm{R} \text { values }\end{array}$ & $\begin{array}{c}\text { Process } \\
\text { acceptability }\end{array}$ \\
\hline $\begin{array}{l}\text { Acceptable } \\
\text { - quality/ } \\
\text { environmental/ } \\
\text { workplace safety } \\
\text { aspect is safe }\end{array}$ & $\begin{array}{l}\mathrm{RI}=1-3 \\
\mathrm{RII}=1-25\end{array}$ & $\begin{array}{c}\Sigma \mathrm{RI}=1-35 \\
\sum \mathrm{R} \|=1-275\end{array}$ & $\begin{array}{l}\text { Acceptable } \\
\text { - process is safe in } \\
\text { the context of fulfilling: } \\
\text { quality, environmental } \\
\text { and workplace safety } \\
\text { requirements }\end{array}$ \\
\hline $\begin{array}{l}\text { Moderate } \\
\text { - quality/ } \\
\text { environmental/ } \\
\text { workplace safety } \\
\text { aspect requires } \\
\text { monitoring }\end{array}$ & $\begin{aligned} \mathrm{RI} & =4-9 \\
\mathrm{R} I & =26-69\end{aligned}$ & $\begin{array}{c}\sum \mathrm{RI}=36-65 \\
\sum \mathrm{R} \|=276-515\end{array}$ & $\begin{array}{l}\text { Moderate } \\
\text { - process requires } \\
\text { monitoring of the } \\
\text { quality, environmental } \\
\text { and workplace safety } \\
\text { aspects }\end{array}$ \\
\hline $\begin{array}{l}\text { Unacceptable } \\
\text { - quality/ } \\
\text { environmental/ } \\
\text { workplace safety } \\
\text { aspect requires } \\
\text { elimination }\end{array}$ & $\begin{aligned} \mathrm{RI} & =10-16 \\
\mathrm{RII} & =70-125\end{aligned}$ & $\begin{array}{c}\sum \mathrm{RI}=66-96 \\
\sum \mathrm{RII}=516-750\end{array}$ & $\begin{array}{l}\text { Unacceptable } \\
\text { - process requires } \\
\text { rearranging, its } \\
\text { realization is hazardous } \\
\text { for workers, } \\
\text { environment and } \\
\text { doesn't guarantee } \\
\text { quality requirements } \\
\text { fulfilment }\end{array}$ \\
\hline
\end{tabular}

Fig. 2. Scheme of assessing risk acceptability of individual aspects and the entire technological process in dependence on the exemplary risk values 


\section{RESULTS AND DISCUSSION}

The described guidance for assessment have been used within the range of polyethylene foil technological process risk assessment. The exemplary faults, environmental influences, outcomes of workplace safety threats and their effects and reasons are following:

- high level of haze - unaesthetic look - damage of cooling ring device (1),

- uneven thickness of foil - breakage of foil - too short time of foil cooling (2),

- occupying the place on the internal waste disposal site till the recycling time producing the foil and cardboard wastes - quality control (3),

- pollution of soil - scattering of the polyethylene granulated product over the ground - improper storage and transportation (4),

- burns - adhesion of the melted granulated product to the skin - ensuring high temperature within the process (5),

- fractures and crushes of limbs - pulling the loose parts of outfit into the movable parts of the winder - foil rolling operations (6),

Descriptive the mentioned above risk parameters for its various ways of assessment have been presented in Table 3.

Table 3

Comparison of the values of risk parameters for different manners of its assessment

\begin{tabular}{|c|c|c|c|c|c|c|c|}
\hline Threat & SI & PI & RI = S·P & SII & PII & DII & RII \\
\hline 1 & 1 & 1 & 1 & 3 & 2 & 6 & 36 \\
\hline 2 & 3 & 1 & 3 & 7 & 2 & 1 & 14 \\
\hline 3 & 1 & 4 & 4 & 1 & 10 & 1 & 10 \\
\hline 4 & 2 & 2 & 4 & 5 & 4 & 1 & 20 \\
\hline 5 & 3 & 1 & 3 & 5 & 2 & 9 & 90 \\
\hline 6 & 4 & 1 & 4 & 7 & 2 & 9 & 126 \\
\hline
\end{tabular}

Risk values for the particular aspects as well as the whole assessed process, including the result of its acceptability assessment, have been presented in Table 4 .

Table 4

Comparison of the effects of risk acceptability assessment

\begin{tabular}{|c|c|c|c|c|}
\hline Threat & RI = S·P & Risk acceptability I & RII & Risk acceptability II \\
\hline 1 & 1 & acceptable & 36 & moderate \\
\hline 2 & 3 & acceptable & 14 & acceptable \\
\hline 3 & 4 & moderate & 10 & acceptable \\
\hline 4 & 4 & moderate & 20 & acceptable \\
\hline 5 & 3 & acceptable & 90 & unacceptable \\
\hline 6 & 4 & moderate & 126 & unacceptable \\
\hline$\sum \mathrm{RI}$ & 19 & acceptable & - & - \\
\hline$\sum \mathrm{RII}$ & - & - & 296 & moderate \\
\hline
\end{tabular}

As it refrains from the comparison (Table 4), while using for the risk assessment just two of its basic parameters (significance of the results and the probability of their 
occurrence) for the threats as unaesthetic look, foil breakage and adhesion of the melted granulated product to the skin, the risk is of the accepted character, however, for foil waste occurrence, scattering of the polyethylene granulated product over the ground as well as pulling the loose parts of outfit into the movable parts of the winder, the risk is moderate and requires monitoring. Value of the risk ratio for whole process totals 19 and is acceptable.

Meanwhile, using for the risk assessment not only its parameters, so making the risk assessment method more detailed enables pointing out as unacceptable as many as two threats effects, which are burns, fractures and crushes of limbs. Simultaneously, total risk ratio value for all the process reaches 296 , risk is moderate and the process requires monitoring, especially these aspects for which the risk is unacceptable or moderate.

\section{CONCLUSIONS}

Nowadays, while estimating the realized or planned processes, one should take into consideration not only the economical and quality parameters but also all which may have influence on fulfilling the requirements stated by the interested parties of the business. As a consequence, this causes the necessity of developing and applying such ways of assessment these processes, which in turn will allow their complex estimation, being in accordance with the needs.

For sure, one of the most effective way for complex assessment is application of the following combination: process approach and risk assessment. Therefore, process approach requires process identification and the assessment outcomes of the risk involved represent the guidance for improving the processes. The risk assessment itself allows not only for pointing out the "risky" processes and their "risky" aspects but also is a base for appointing the parameters undergoing the monitoring process.

It is of high importance to make the applied risk assessment method adequate to the estimated processes. For example, in the study, one has presented two various methodologies for risk assessment, which have been applied for analysing the same process considering the same chosen threats. The methodologies were different in the scope of analysis, especially in range of the risk parameters and the individual criteria for these parameters assessment. In the first case, the calculation algorithm for the values of the single risk ratio covered solely the significance of the threat effects and the probability of their occurrence, the scale of the particular parameters was four-staged. In the second case, the risk analysis considered also its other parameters such as: detect ability or exposition, whereby the individual assessment criteria have been assigned to the ten-stage scale.

Risk acceptability has been defined based on the prepared for both methodologies acceptability scale. The outcomes of the assessment have confirmed that the assessment of two basic risk parameters reflects just general view at the process risk. The more parameters undergo the assessment and the more precise are the assessment criteria, the more detailed is the information on the risk, and especially on the threats causing the risk, and which should be monitored.

Therefore, one should conclude that the following factors are of the highest importance during the process risk assessment:

- choice of such risk parameters which reflect the real risk,

- development of the assessment criteria for these parameters,

- preparation of the risk acceptability scale, adequate to the improvement phase. 
Development of effective risk assessment method, refraining from both: particular threats within the technological process as well as all the technology can be regarded as just a starting point for improving these processes.

\section{REFERENCES}

Gawlik, J., Plichta, J., Świć, A., 2013. Production processes, Polish Economic Publishers, Warsaw.

Grajewski, P., 2012. Process management of organizations, Polish Economic Publishers, Warsaw.

Hernas, A., Gajda, L., 2005. Quality management systems, Silesian Technical University Publishing House, Gliwice.

Karkoszka, T., 2017. Operational control with application of the risk analysis in the integrated management system of technological process, Silesian Technical University Publishing House, Gliwice.

Lisichkina, Y., 2015. Process approach to management of modern organizations, International Conference on Economics, Management, Law and Education,Advances in Social Science, Education and Humanities Research, Atlantis Press B.V., Amsterdam, DOI: 10.2991/emle-15.2015.50

Renn, O., Benighaus, Ch., 2013. Perception of technological risk: insights from research and lessons for risk communication and management, Journal of Risk Research, 16, 293-313, DOI: 10.1080/13669877.2012.729522

Skrzypek, E., 2008. Processes management of a modern enterprise, Maria CurieSkłodowska University Publishing House, Lublin.

Skrzypek, E., Hofman, M., 2010. Processes management in an enterprise. Identification, measurement, improvement, Wolters Kluwer Business, Warsaw.

Zymonik, Z., Hamrol, A., Grudowski, P., 2013. Quality and occupational safety management, Polish Economic Publishers, Warsaw.

ISO 9001, 2015. Quality management systems - Requirements, International Organization for Standardization, Geneva.

IEC 60300-3-9, 1995. Dependability management. Application guide. Risk analysis of technological systems, International Electrotechnical Commission, Geneva. 